\title{
Risk Factors for 30-Day Non-Neurological Morbidity and Cerebrospinal Fluid Leak in Patients Undergoing Surgery for Vestibular Schwannoma
}

\author{
Yaroslav Gelfand ${ }^{1}$ Michael Longo ${ }^{20}$ Naomi Berezin ${ }^{3}$ Jonathan P. Nakhla ${ }^{4}$ \\ Rafael De la Garza-Ramos ${ }^{1}$ Vijay Agarwal ${ }^{1}$ \\ ${ }^{1}$ Leo M. Davidoff Department of Neurosurgery, Montefiore Medical \\ Center/Albert Einstein College of Medicine, Bronx, New York, Unites States \\ ${ }^{2}$ Albert Einstein College of Medicine, Yeshiva University, Bronx, New \\ York, United States \\ ${ }^{3}$ Department of Surgery, Montefiore Medical Center, Bronx, New \\ York, United States \\ ${ }^{4}$ Department of Neurosurgery, Rhode Island Hospital, Providence, \\ Rhode Island, United States

\begin{abstract}
Address for correspondence Vijay Agarwal, MD, Leo M. Davidoff Department of Neurosurgery, Montefiore Medical Center/Albert Einstein College of Medicine, 3316 Rochambeau Ave, Bronx, NY 10467, Unites States (e-mail: vjagarwal@gmail.com).
\end{abstract} \\ J Neurol Surg B 2020;81:546-552.
}

\begin{abstract}
Keywords

- vestibular schwannoma

- complications

- CSF leak

- reoperation

Introduction We analyzed perioperative risk factors for morbidity and mortality for the patients undergoing surgical intervention for vestibular schwannoma along with rates of cerebrospinal fluid (CSF) leaks that required surgery.

Materials and Methods Patients undergoing surgery vestibular schwannoma were identified in the American College of Surgeons National Surgical Quality Improvement Program database from 2012 to 2016 using current procedural terminology (CPT) codes for posterior fossa surgical approaches and International Classification of Diseases 9th revision (ICD 9) and ICD 10 codes for peripheral nerve sheath tumor. Preoperative laboratories, comorbidities, and operative times were analyzed along with CSF leaks and unplanned returns to the operating room.

Results Nine-hundred ninety-three patients fit the inclusion criteria. Average age was $51,41 \%$ were male, and $58 \%$ were female. Mortality within 30 days of the operation was very low at $0.4 \%$, complications were $7 \%$ with infection being the most common at $2.3 \%$, and unplanned reoperations happened in $7.4 \%$ of the cases. Dependent functional status (odds ratio [OR]: 5.7, 95\% confidence interval [CI]: 1.9-16.6, $p=0.001$ ), preoperative anemia (OR: $2.4,95 \% \mathrm{Cl}: 1.2-4.5, p=0.009$ ), and operative time over 8 hours (OR: $1.9,95 \% \mathrm{Cl}: 1.1-3.4, p=0.017$ ) were the only significant predictors of perioperative complications. CSF leak postoperatively occurred in 37 patients (3.7\%). Reoperation for CSF leak was necessary in $56.3 \%$ of the cases. Operative time over 8 hours was the only independent significant predictor of postoperative CSF leak (OR: 2.2, 95\% Cl: $1.1-4.3, p=0.028)$.
\end{abstract}

received

February 24, 2019

accepted after revision

May 11, 2019

published online

June 21, 2019 (c) 2020 Georg Thieme Verlag KG

Stuttgart · New York
DOI https://doi.org/

10.1055/s-0039-1692478. ISSN 2193-6331. 
Conclusion Dependent functional status preoperatively, preoperative anemia, and duration of surgery over 8 hours are the greatest predictors of complications in the 30 day postoperative period.

\section{Introduction}

Refinement of surgical techniques in vestibular schwannoma (VS) resection in the past 50 years has significantly improved the outcomes with morbidity under $10 \%$ and mortality between 0.8 and $5 \%$ depending on tumor characteristics. ${ }^{1-3}$ While the majority of reports focus on neurologic outcomes, few analyze non-neurologic morbidity and CSF leak propensity in VS. Those that do usually rely on a single institutional experience. $^{4-6}$

We reviewed a large multicenter patient sample to analyze potential predictors of non-neurologic morbidity, mortality, return to the operating room, and CSF leak incidence and repair strategies in patients undergoing surgery for VS resection.

\section{Methods}

\section{Study Design and Data Source}

This is a retrospective multicenter study using the American College of Surgeons National Surgical Quality Improvement Program (ACS-NSQIP) database from 2006 to 2016. This study was deemed exempt from review by the local institutional review board (2016-6862). Consent requirements were waived since ACS-NSQIP data are deidentified. We used the International Classification of Diseases 9th revision (ICD 9) (225.1) and ICD 10 (G33.3) codes for benign neoplasm of cranial nerve and the CPT codes for craniectomy for cerebellar-pontine angle (CPA) angle tumor (61520), resection of lesion at scull base (61616), along with the CPT codes for a transtemporal/translabyrinthine (TL) approach to CPA $(61526,61530)$ to identify adult patients (age over 18$)$ who underwent craniotomy for VS. The NSQIP variable for return to the operating room along with the variable for the corelating CPT codes for return to the operating room was analyzed as well.

\section{Collected Data}

Demographic data collected included age, gender, preoperative functional status (dependent versus independent), and body mass index (BMI). BMI was separated into two categories: normal (BMI $<30 \mathrm{~kg} / \mathrm{m}^{2}$ ) or obese $\left(\mathrm{BMI} \geq 30 \mathrm{~kg} / \mathrm{m}^{2}\right)$. Medical comorbidities analyzed included diabetes, history of hypertension requiring medication, chronic obstructive pulmonary disease, congestive heart failure, history of smoking, chronic steroid use, and dialysis. Perioperative complications reviewed were deep or superficial surgical site infection, wound dehiscence, sepsis, pneumonia, urinary tract infection, renal complications (acute kidney injury and renal failure), deep venous thrombosis, septic shock, myocardial infarction, cardiac arrest, stroke, pulmonary embolism, and prolonged ventilation (over 48 hours).
Operative data included utilization of a TL approach and operative time. Laboratory data reviewed included hematocrit (Hct) and white blood cell count (WBC). Anemia was defined as Hct $<40 \%$ in males and $<36 \%$ in females. ${ }^{7}$ Our primary outcome measures was 30-day non-neurologic morbidity.

Our secondary outcome measure was cerebrospinal fluid (CSF) leak. We used NSQIP variables for readmission and reoperation of ICD 9 and ICD 10 codes for CSF leak (349.81 and G96.0, respectively) along with reoperation CPT codes for CSF leak (61618 and 62100) to identify patients who were readmitted or required reoperation for CSF leak.

Our tertiary analysis included comparison between patients who underwent a TL approach with or without craniotomy with those who underwent craniotomy alone for perioperative complications and CSF leaks specifically.

\section{Statistical Analysis}

All statistical analysis was performed using STATA 13.0 (Stata Corp LLC, College Station, Texas, United States). Descriptive statistics were used to describe the study population. Factors associated with 30-day morbidity, mortality, and CSF leak were assessed via univariate analyses. Comparisons were made via chi-squared tests, Fisher's exact test, or student $t$ tests as appropriate and any factor with a $p$-value $\leq 0.05$ was then included in a multivariate regression model to identity independent predictors of outcome. Secondary analyses included a comparison in CSF leaks between patients who underwent $\mathrm{TL}$ approaches with or without craniotomy to those who underwent craniotomy alone.

\section{Results}

A total of 993 patients who underwent surgery for resection of VS were identified from 2006 to 2016. Average age for all patients was 50.6 years $-41.4 \%$ were male, and $58.6 \%$ were female. Average BMI was $29.6 \mathrm{~kg} / \mathrm{m}^{2}$. The three most common comorbidities overall were hypertension (31.9\%), smoking (9.8\%), and diabetes (8.7\%). Average WBC and Hct were 7.3 cells $/ \mu \mathrm{L}$ and $41.3 \%$, respectively (-Table 1 ). About $11.3 \%$ of patients were anemic. The overall complication rate was $14.8 \%$, with surgical site infection being most common complications at $2.3 \%$ (-Table 2). The 30-day mortality rate was very small at $0.4 \%$. The percentage of patients with CSF leak was 3.7\% and those who needed a reoperation within the 30 -day period was $7.4 \%$ (-Table 2 ).

\section{Factors Associated with Morbidity}

The univariate analysis for risk factors associated with overall nonoperative morbidity can be found in -Table 3. While further analyzing operative times, we noted that $75 \%$ of 
Table 1 Demographics, laboratory, and operative data

\begin{tabular}{|l|l|}
\hline Number of cases & 993 \\
\hline Mean age & 50.6 \\
\hline Male sex (\%) & 41.4 \\
\hline Female sex (\%) & 58.6 \\
\hline WBC average (cells/ $\mu \mathrm{L})$ & 7.3 \\
\hline Hematocrit average (\%) & 41.3 \\
\hline Anemia (\%) & 11.3 \\
\hline Dependent functional status (\%) & 1.8 \\
\hline Comorbidities & \\
\hline Diabetes (\%) & 8.7 \\
\hline Hypertension (\%) & 31.9 \\
\hline COPD (\%) & 0.4 \\
\hline Heart failure (\%) & 0 \\
\hline Smoking (\%) & 9.8 \\
\hline Chronic steroid use (\%) & 4.6 \\
\hline Hemodialysis (\%) & 0 \\
\hline Body mass index (kg/m ${ }^{2}$ ) & 29.6 \\
\hline Emergency procedure (\%) & 0.5 \\
\hline $\begin{array}{l}\text { Translabyrinthine with or with- } \\
\text { out craniotomy (\%) }\end{array}$ & 33.7 \\
\hline Craniotomy alone (\%) & 66.3 \\
\hline Operative time (mean hours) & 6.6 \\
\hline
\end{tabular}

Abbreviations: COPD, chronic obstructive pulmonary disease; WBC, white blood cell.

operations were $<8$ hours long. With operative time showing significance as predictor of complications, we chose 8 hours as a cutoff point to dichotomize operative time variables. On multivariate analysis that included age, gender, and predictors that were statistically significant from - Table 3, dependent functional status (odds ratio [OR]: 5.7, 95\% CI: 1.9-16.6, $p=0.001$ ), anemia (OR: 2.4, 95\% CI: $1.2-4.5$ ), and operative time over 8 hours (OR: 1.9 , $95 \% \mathrm{CI}: 1.1-3.4, p=0.017$ ) were statistically significant risk factors for overall complications (-Table 5).

\section{Analysis of the Translabyrinthine Approach and CSF Leaks}

There was no difference in overall complications or mortality ( - Table 2) between patients who underwent a TL approach with or without craniotomy (translab group) and those who underwent craniotomy alone (craniotomy group). CSF leak, however, approached statistical significance $(p=0.051)$. On the univariate analysis for risk factors associated with the CSF leak found in - Table 4, another factor that turned out to be significant was operative time ( $p=0.008)$. Of note, there was a statistically significant difference in average operative times between TL and no TL group: 6.5 hours in TL group versus 6.9 hours in non-TL group, $p=0.039$. As in prior sections we split operative time into two groups: over 8 hours and under 8 hours. On multivariate analysis (-Table 5), however, a TL approach failed to reach statistical significance $(p=0.075)$. Operative time over 8 hours was the only identified predictor of CSF leak in patients undergoing operation for VS $(p=0.028)$. Further analysis of CSF leak revealed that 27 (73.0\%) required a return to the operating room (-Table 6). Sixteen patients (43.2\%) required craniotomy for CSF leak repair. CSF leak relevant procedures were done in 21 cases of CSF leak (56.7\%). We assume the remainder of the leaks (43.3\%) were fixed with nonoperative measures (such as a lumbar drain).

\section{Discussion}

\section{Non-Neurological Morbidity}

Although the overall complication rate following VS resection approaches $30 \%,{ }^{8,9}$ medical complication rates in contemporary studies are consistently below $10 \% .{ }^{9-11}$ While this is in line with our reported rate of $7.1 \%$, few studies have examined risk factors for non-neurological morbidity distinctly. Mahboubi et al reported a non-neurological complication rate of $5.1 \%$ following VS resection in their study of the California Hospital Inpatient Discharge Dataset, yet only reported risk factors related to general administrative information. ${ }^{9}$ More recently, Sylvester et al reported a medical complication rate of $9.8 \%$ and determined that such complications occurred significantly more often in patients aged $\geq 65$ years compared with $<65$ years $(22.7$ vs. $7.9 \%$, $p<0.01) .^{10}$ Acute cardiac events were the most common medical complication, occurring far more often in the elderly group (10.8 vs. $1.9 \%, p<0.001) .^{10}$ Our results differ from those of Sylvester et al, as age was not associated with increased non-neurological morbidity ( $p=0.59$ in univariate). Additionally, the rate of major cardiac events (myocardial infarction or cardiac arrest) was very low in our study ( 0.3 and $0.2 \%$, respectively). These differences may be a product of different study populations and outcome measures. The present study did, however, identify several other significant predictors of non-neurological morbidity. Dependent functional status, anemia preoperatively, and duration of surgery over 8 hours demonstrated 5.7, 2.4, and 1.9 times increased odds of medical complications, respectively. While dependent functional status and operative time may be dependent on the patient and tumor size and cannot be corrected, anemia is a potentially modifiable factor that more than doubles the risk of postoperative complications.

Prior studies have identified preoperative anemia as a predictor of postoperative complications, prolonged length of stay, and readmission rates in neurosurgical procedures. $^{12,13}$ Spine literature also has included preoperative anemia as a modifiable risk factor to reduce complications and optimize recovery. ${ }^{14-16}$ They have found that preoperative anemia is an independent risk factor for complications and prolonged lengths of stay in lumbar fusions, posterior cervical fusions, and deformity surgery. While overall risk of blood and transfusions is low in VS surgery $(2.1 \%$ in this cohort), preoperative anemia persisted as an independent predictive factor for postoperative complications. Performing appropriate workup and correcting potential causes of 
Risk Factors for Morbidity and Mortality for the Patients Undergoing Surgery for VS Gelfand et al. 549

Table 2 Non-neurologic morbidity, mortality, CSF leak, and return to the operating room

\begin{tabular}{|l|l|l|l|l|}
\hline Complication & Overall & $\begin{array}{l}\text { No translab ap- } \\
\text { proach }\end{array}$ & $\begin{array}{l}\text { Translab ap- } \\
\text { proach with/ } \\
\text { without cra- } \\
\text { niotomy }\end{array}$ & $p$-Value \\
\hline $\begin{array}{l}\text { Deep or superficial surgical site } \\
\text { infection (\%) }\end{array}$ & 2.3 & 2.3 & 2.4 & 0.914 \\
\hline Wound dehiscence (\%) & 0.6 & 0.5 & 0.9 & 0.398 \\
\hline Sepsis (\%) & 1.8 & 2.3 & 0.9 & 0.122 \\
\hline Septic shock (\%) & 0.2 & 0.2 & 0.3 & 0.626 \\
\hline Pneumonia (\%) & 1.0 & 1.4 & 0.3 & 0.111 \\
\hline $\begin{array}{l}\text { Reintubation after the operating } \\
\text { room (\%) }\end{array}$ & 1.2 & 1.4 & 0.9 & 0.520 \\
\hline Pulmonary embolism (\%) & 0.4 & 0.5 & 0.3 & 0.711 \\
\hline Cerebrovascular incident (\%) & 0.3 & 0.3 & 0.3 & 0.988 \\
\hline Myocardial infarction (\%) & 0.3 & 0.3 & 0.3 & 0.988 \\
\hline Cardiac arrest (\%) & 0.2 & 0.3 & 0 & 0.312 \\
\hline Urinary tract infection & 0.9 & 1.1 & 0.6 & 0.463 \\
\hline Renal insufficiency (\%) & 0 & 0 & 0 & $\mathrm{n} / \mathrm{a}$ \\
\hline Deep venous thromboses (\%) & 1.2 & 0.8 & 2.1 & 0.070 \\
\hline Overall complications (\%) & 7.1 & 7.9 & 5.4 & 0.141 \\
\hline Blood transfusions (\%) & 2.1 & 2.6 & 1.2 & 0.150 \\
\hline CSF leak (\%) & 3.7 & 2.9 & 5.4 & $0.051^{\text {a }}$ \\
\hline Mortality (\%) & 0.4 & 0.6 & 0.153 \\
\hline Return to the operating room (\%) & 7.4 & 7.5 & 7.2 & 0.872 \\
\hline
\end{tabular}

${ }^{a}$ Statistically significant.

Abbreviation: CSF, cerebrospinal fluid.

preoperative anemia have been advocated in other specialties to reduce postoperative complications. ${ }^{17,18}$ While further studies are needed, patients evaluated for VS surgery may benefit from hematologic workup and anemia correction preoperatively.

\section{CSF Leak}

Reported rates of CSF leak following VS resection in the literature are quite variable: studies reported 2.4 to $12.0 \%$ in recent literature. ${ }^{2,4-6,8-10}$ The rate of CSF leak was observed to be significantly higher in TL approaches for VS., ${ }^{4,5}$ While we observed a difference in CSF leak rates between TL group and no TL group (-Table 2 ), that difference was not statistically significant on multivariate regression analysis controlling for age, gender, and operative time. As mentioned in our results, the operative times were longer on average for the TL group and that may have accounted for the higher risk of CSF leaks in our data.

Among the most common approaches to VS, multiple reconstruction techniques to prevent CSF fistula may be utilized, including primary closure, fibrin glue, fat or temporalis muscle grafting, air cell obliteration with bone wax, and/or hydroxyapatite cement. ${ }^{19-21}$ Selesnick et al ${ }^{19}$ provide a comprehensive meta-analysis that examines the prophylactic surgical techniques in VS surgery. Although the authors note that techniques, such as hydroxyapatite closure, ${ }^{21,22}$ have yielded promising results, no specific technique has consistently demonstrated a relationship with significantly reduced CSF leak rates. ${ }^{19}$

In terms of predictors unrelated to operative approach, several risk factors have been identified in the literature, like BMI, age, and operative time. Copeland et al determined that CSF leaks were more likely to occur in patients with higher BMI. ${ }^{4} \mathrm{He}$ also found operative times to have a slight impact on the CSF leak (OR: 1.04). Russel et al identified males and younger patients as demographics at greater risk in a TL approach cohort. ${ }^{5} \mathrm{He}$ found that surgical times had a more significant impact on CSF leaks (OR: 1.85). Our findings corroborate prior findings that prolonged surgical time increases the likelihood of CSF leak. ${ }^{4,5}$ While no specific numbers are mentioned in prior papers, we chose the 75th percentile of operative duration for our cutoff point and found that operative time $>8$ hours was associated with 1.8 times increased risk of CSF leak.

Several explanations for prolonged operative times contributing to the CSF have been proposed in the literature. Brennan et al have showed that tumor size can affect both the rates of CSF leak and operative times. ${ }^{23}$ We do not have the information about the tumor size in our cohort, but it might be that those requiring longer operations had a larger, more 
550 Risk Factors for Morbidity and Mortality for the Patients Undergoing Surgery for VS Gelfand et al.

Table 3 Univariate analysis for predictors of complications

\begin{tabular}{|l|l|l|l|}
\hline Variable & No complications & Complications & $p$-Value \\
\hline Age & 50.7 & 49.7 & 0.594 \\
\hline Male (\%) & 40.9 & 48.6 & 0.206 \\
\hline Female (\%) & 59.2 & 51.4 & 0.206 \\
\hline WBC average (cells/ $\mathrm{LL}$ ) & 7.3 & 7.6 & 0.369 \\
\hline Hematocrit average (\%) & 41.4 & 40.1 & $0.021^{\mathrm{a}}$ \\
\hline Anemia (\%) & 10.4 & 23.1 & $0.002^{\mathrm{a}}$ \\
\hline Dependent functional status (\%) & 1.2 & 10.0 & $<0.001^{\mathrm{a}}$ \\
\hline Comorbidities & & & \\
\hline Diabetes (\%) & 8.7 & 8.6 & 0.978 \\
\hline Hypertension (\%) & 31.2 & 41.4 & 0.077 \\
\hline COPD (\%) & 0.3 & 1.4 & 0.160 \\
\hline Heart failure (\%) & 0 & 0 & $\mathrm{n} / \mathrm{a}$ \\
\hline Smoking (\%) & 10.1 & 5.7 & 0.236 \\
\hline Chronic steroid use (\%) & 4.4 & 7.1 & 0.300 \\
\hline Hemodialysis (\%) & 0 & 0 & $\mathrm{n} / \mathrm{a}$ \\
\hline Body mass index (average) & 29.5 & 30.7 & 0.156 \\
\hline Emergency procedure (\%) & 0.5 & 0 & 0.537 \\
\hline Translabyrinthine approach (\%) & 34.3 & 25.7 & 0.141 \\
\hline Operative time (hours) & 6.5 & 7.7 & $<0.001^{\mathrm{a}}$ \\
\hline
\end{tabular}

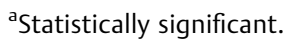

Abbreviations: COPD, chronic obstructive pulmonary disease; WBC, white blood cell.

Table 4 Univariate analysis for predictors of CSF leak

\begin{tabular}{|l|l|l|l|}
\hline Variable & No Leak & Leak & $p$-Value \\
\hline Age & 50.5 & 52.1 & 0.508 \\
\hline Male (\%) & 43.2 & 41.3 & 0.816 \\
\hline Female (\%) & 58.7 & 56.8 & 0.816 \\
\hline WBC average (cells/ $\mathrm{LL})$ & 7.3 & 7.2 & 0.763 \\
\hline Hematocrit average (\%) & 41.3 & 41.0 & 0.652 \\
\hline Anemia (\%) & 11.1 & 15.2 & 0.473 \\
\hline Dependent functional status (\%) & 1.9 & 0 & 0.400 \\
\hline Comorbidities & & & \\
\hline Diabetes (\%) & 8.6 & 10.8 & 0.636 \\
\hline Hypertension (\%) & 31.6 & 40.5 & 0.252 \\
\hline COPD (\%) & 0.4 & 0 & 0.693 \\
\hline Heart failure (\%) & 0 & 0 & n/a \\
\hline Smoking (\%) & 9.9 & 5.4 & 0.362 \\
\hline Chronic steroid use (\%) & 4.7 & 2.7 & 0.569 \\
\hline Hemodialysis (\%) & 0 & 0 & n/a \\
\hline Body mass index (average) & 29.6 & 30.5 & 0.419 \\
\hline Emergency procedure (\%) & 0.5 & 0 & 0.659 \\
\hline Translabyrinthine approach (\%) & 33.2 & 48.7 & $0.051^{\mathrm{a}}$ \\
\hline Operative time (hours) & 6.6 & 7.7 & $0.008^{\mathrm{a}}$ \\
\hline
\end{tabular}

Abbreviations: COPD, chronic obstructive pulmonary disease; WBC, white blood cell. complex masses. There are several other studies, however, that suggest that tumor size and staging do not influence the risk of CSF leak, and thus the effect of tumor size on operative time is not an issue at hand. ${ }^{19,24}$ Russel et al postulated that longer operative times result in blood accumulation in the basal cisterns, leading to the problems with CSF absorption potentially contributing to hydrocephalus and CSF leak. ${ }^{5}$ They also postulated that surgeon fatigue by the end of the longer case may lead to suboptimal closure techniques.

Unlike prior studies, neither BMI, gender, nor age achieved significance in our univariate analysis for CSF leak risk factors. Although it is not possible to determine

Table 5 Multivariate regression results for complication and CSF leak controlling for statistically significant predictors from univariate analysis

\begin{tabular}{|c|c|l|l|}
\hline Complications & OR & $95 \% \mathrm{Cl}$ & $p$-Value \\
\hline Dependent functional status & 5.7 & $1.9-16.6$ & 0.001 \\
\hline Anemia & 2.4 & $1.2-4.5$ & 0.009 \\
\hline Operative time over 8 hours & 1.9 & $1.1-3.4$ & 0.017 \\
\hline CSF leak & & & \\
\hline Translabyrinthine approach & 1.8 & $0.9-3.5$ & 0.075 \\
\hline Operative time over 8 hours & 2.2 & $1.1-4.3$ & 0.028 \\
\hline
\end{tabular}

Abbreviations: $\mathrm{Cl}$, confidence interval; CSF, cerebrospinal fluid; OR, odds ratio. 
Risk Factors for Morbidity and Mortality for the Patients Undergoing Surgery for VS Gelfand et al. 551

Table 6 Reason for return to the operating room in patients with CSF leak

\begin{tabular}{|l|l|}
\hline Total CSF leaks & 37 \\
\hline Returned to the operating room & $27(73 \%)$ \\
\hline CPT code for reoperation & 1 \\
\hline 21230 (cartilage graft to Face) & $9(24.3 \%)$ \\
\hline 61618 (secondary repair of dura for cerebrospinal fluid leak) & $7(18.9 \%)$ \\
\hline 62100 (craniotomy for repair of dural/cerebrospinal fluid leak) & $1(2.7 \%)$ \\
\hline 67912 (gold weight implant) & $1(2.7 \%)$ \\
\hline 69140 (excision exostosis) & $1(2.7 \%)$ \\
\hline 69511 (mastoidectomy) & $1(2.7 \%)$ \\
\hline 69620 (myringoplasty) & $1(2.7 \%)$ \\
\hline 69700 (closure postauricular fistula, mastoid) & $5(13.5 \%)$ \\
\hline Unknown & $20(54.1 \%$ of CSF leaks) \\
\hline Returned to the operating room for CSF leak repair & \\
\hline
\end{tabular}

Abbreviations: CSF, cerebrospinal fluid.

the exact cause of this disparity, perhaps the multicenter nature of our cohort is different from a single institutional sample such as in the Copeland et al study. Additionally, the present study population and that from Russel et al differ, as we analyzed a heterogenous cohort, and Russel's consisted of patients that only underwent TL approaches. ${ }^{5}$

We did not identify any prior studies that discuss the rate of the return to the operating room for patients that suffered from postoperative CSF leak in patients who had VS surgical resected. We found that $54.1 \%$ of patients returned to the operating room for CSF leak repairs. The rest went back to the OR for other procedures (like a gold weight). Unfortunately, one of the limitations of a large national database analysis is the lack of the ability to further investigate how the rest of the leaks were specifically treated. We presume since $54.1 \%$ required surgical repair; the other $45.9 \%$ were treated nonoperatively such as by lumbar CSF drainage.

\section{Limitations}

There are several limitations in our study most of which are inherent to the NSQIP database. First the data are only collected from the institutions that participate in NSQIP; thus, the complication rates and mortality may vary on the national level. Second, the database only considers the complications, mortalities, and readmissions in the 30 -day period postoperatively, and all the events after that period of time are missed or not recorded. Third, the data are captured using billing codes like ICD 9 and 10 along with CPTs, which are known to be prone to errors, omissions, and often lack the specificity. In our selection process, we used ICD 9 and 10 codes for benign neoplasms of the cranial nerves. However, those do not differentiate VS patients from the ones with trigeminal or facial nerve schwannomas. While the later are quite rare, we do not have a good way of excluding them from the study. Finally, an important information about tumor size, staging, neurologic comorbidities, and prior surgery, all of which can influence the complexity of the operation are not available in the database.

\section{Conclusion}

In this study, we identified preoperative anemia and dependent functional status as independent risk factors for postoperative complications in VS surgery patients, while confirming prior implications of prolonged operative time in increased complication rates. We also determined that over $40 \%$ of postoperative CSF leaks are managed nonoperatively, while the rest required surgical intervention. Although further studies are needed to validate our results, we believe this information may aid in patient counseling, stratification of operative risk, perioperative planning, optimization, and enhanced postoperative recovery.

\section{Disclaimer}

The manuscript submitted does not contain information about medical device(s)/drug(s).

\section{Funding}

No funds were received in support of this work.

Conflict of Interest

None declared.

\section{References}

1 House JW, Nissen RL, Hitselberger WE. Acoustic tumor management in senior citizens. Laryngoscope 1987;97(02):129-130

2 Sughrue ME, Yang I, Aranda D, et al. Beyond audiofacial morbidity after vestibular schwannoma surgery. J Neurosurg 2011;114(02): 367-374

3 Wiet RJ, Teixido M, Liang JG. Complications in acoustic neuroma surgery. Otolaryngol Clin North Am 1992;25(02):389-412

4 Copeland WR, Mallory GW, Neff BA, Driscoll CL, Link MJ. Are there modifiable risk factors to prevent a cerebrospinal fluid leak following vestibular schwannoma surgery? J Neurosurg 2015; 122(02):312-316

5 Russel A, Hoffmann CP, Nguyen DT, Beurton R, Parietti-Winkler C. Can the risks of cerebrospinal fluid leak after vestibular schwannoma surgery be predicted? Otol Neurotol 2017;38(02):248-252 
6 Xia Y, Zhang W, Li Y, Ma X, Liu Q, Shi J. The transotic approach for vestibular schwannoma: indications and results. Eur Arch Otorhinolaryngol 2017;274(08):3041-3047

7 Walker WB. The Oral Cavity and Associated Structures. In: Walker HK, Hall WD, Hurst JW, editors. Clinical Methods: The History, Physical, and Laboratory Examinations. 3rd edition. Boston: Butterworths; 1990. Chapter 129

8 Kunert P, Dziedzic T, Czernicki T, Nowak A, Marchel A. Surgery for sporadic vestibular schwannoma. Part II. Complications (not related to facial and auditory nerves). Neurol Neurochir Pol 2016;50(02):90-97

9 Mahboubi H, Ahmed OH, Yau AY, Ahmed YC, Djalilian HR. Complications of surgery for sporadic vestibular schwannoma. Otolaryngol Head Neck Surg 2014;150(02):275-281

10 Sylvester MJ, Shastri DN, Patel VM, et al. Outcomes of vestibular schwannoma surgery among the elderly. Otolaryngol Head Neck Surg 2017;156(01):166-172

11 Charpiot A, Tringali S, Zaouche S, Ferber-Viart C, Dubreuil C. Perioperative complications after translabyrinthine removal of large or giant vestibular schwannoma: outcomes for 123 patients. Acta Otolaryngol 2010;130(11):1249-1255

12 Hersh EH, Sarkiss CA, Ladner TR, et al. Perioperative risk factors for thirty-day morbidity and mortality in the resection of extradural thoracic spine tumors. World Neurosurg 2018;120: e950-e956

13 Lopez Ramos C, Brandel MG, Rennert RC, et al. Clinical risk factors and postoperative complications associated with unplanned hospital readmissions after cranial neurosurgery. World Neurosurg 2018;119:e294-e300

14 Elsamadicy AA, Adogwa O, Ongele M, et al. Preoperative hemoglobin level is associated with increased health care use after elective spinal fusion ( $\geq 3$ levels) in elderly male patients with spine deformity. World Neurosurg 2018;112:e348-e354

15 Khanna R, Harris DA, McDevitt JL, et al. Impact of anemia and transfusion on readmission and length of stay after spinal sur- gery: a single-center study of 1187 operations. Clin Spine Surg 2017;30(10):E1338-E1342

16 Phan K, Dunn AE, Kim JS, et al. Impact of preoperative anemia on outcomes in adults undergoing elective posterior cervical fusion. Global Spine J 2017;7(08):787-793

17 Muñoz M, Gómez-Ramírez S, Kozek-Langeneker S. Pre-operative haematological assessment in patients scheduled for major surgery. Anaesthesia 2016;71(Suppl 1):19-28

18 Goodnough LT, Maniatis A, Earnshaw P, et al. Detection, evaluation, and management of preoperative anaemia in the elective orthopaedic surgical patient: NATA guidelines. Br J Anaesth 2011; 106(01):13-22

19 Selesnick SH, Liu JC, Jen A, Newman J. The incidence of cerebrospinal fluid leak after vestibular schwannoma surgery. Otol Neurotol 2004;25(03):387-393

20 Baird CJ, Hdeib A, Suk I, et al. Reduction of cerebrospinal fluid rhinorrhea after vestibular schwannoma surgery by reconstruction of the drilled porus acusticus with hydroxyapatite bone cement. J Neurosurg 2007;107(02):347-351

21 Manjila S, Weidenbecher M, Semaan MT, Megerian CA, Bambakidis NC. Prevention of postoperative cerebrospinal fluid leaks with multilayered reconstruction using titanium mesh-hydroxyapatite cement cranioplasty after translabyrinthine resection of acoustic neuroma. J Neurosurg 2013;119(01):113-120

22 Arriaga MA, Chen DA, Burke EL. Hydroxyapatite cement cranioplasty in translabyrinthine acoustic neuroma surgery-update. Otol Neurotol 2007;28(04):538-540

23 Brennan JW, Rowed DW, Nedzelski JM, Chen JM. Cerebrospinal fluid leak after acoustic neuroma surgery: influence of tumor size and surgical approach on incidence and response to treatment. J Neurosurg 2001;94(02):217-223

24 Becker SS, Jackler RK, Pitts LH. Cerebrospinal fluid leak after acoustic neuroma surgery: a comparison of the translabyrinthine, middle fossa, and retrosigmoid approaches. Otol Neurotol 2003; 24(01):107-112 